\title{
Adipose-derived stem cells and hyaluronic acid based gel compatibility, studied in vitro
}

\author{
JIAYAN GUO ${ }^{1}$, SHU GUO ${ }^{1}$, YUXIN WANG $^{1}$ and YANQIU YU ${ }^{2}$ \\ ${ }^{1}$ Department of Plastic Surgery, First Hospital of China Medical University; \\ ${ }^{2}$ Department of Pathophysiology, China Medical University, Heping, Shenyang, Liaoning 110001, P.R. China
}

Received February 17, 2016; Accepted February 22, 2017

DOI: $10.3892 / \mathrm{mmr} .2017 .7055$

\begin{abstract}
Minimally invasive aesthetic and cosmetic procedures have increased in popularity. Injectable dermal fillers provide soft tissue augmentation, improve facial rejuvenation and wrinkles, and correct tissue defects. To investigate the use of adipose-derived stem cells integrated with a hyaluronic acid based gel as a dermal filler, the present study used cytotoxicity studies, proliferation studies, adipogenic and osteogenic differentiation, apoptosis assays and scanning electron microscopy. Although hyaluronic acid induced low levels of apoptosis in adipose-derived stem cells, its significantly promoted proliferation of adipose-derived stem cells. Hyaluronic acid demonstrates little toxicity against adipose-derived stem cells. Adipose-derived stem cells were able to differentiate into adipocytes and osteoblasts. Furthermore, scanning electron microscopy revealed that adipose-derived stem cells maintained intact structures on the surface of hyaluronic acid as well as in it, and demonstrated abundant cell attachments. The present study demonstrated the compatibility of adipose-derived stem cells and hyaluronic acid based gels in vitro.
\end{abstract}

\section{Introduction}

In the last decade, minimally invasive aesthetic and cosmetic procedures have increased in popularity due to their speed and safety. Injectable dermal fillers provide soft tissue augmentation, improve facial rejuvenation and wrinkles and correct tissue defects including scars and lipoatrophy (1). An ideal implant should provide structural support and be safe, effective, long-lasting and biocompatible. Research in the field of tissue engineering has demonstrated that it appears increasingly possible to use multipotent stem cells for injectable

Correspondence to: Dr Yuxin Wang, Department of Plastic Surgery, First Hospital of China Medical University, 155 Nanjing North Road, Heping, Shenyang, Liaoning 110001, P.R. China E-mail:wyx6431@hotmail.com

Key words: adipose-derived stem cells, hyaluronic acid based gels, compatibility study, injectable dermal fillers, in vitro dermal fillers. Adipose-derived stem cells are an attractive cell resource as they have an abundant source, are easy to isolate from fat tissue and inject immediately post-isolation, are able to proliferate at a high rate, and possess multipotent differentiation properties when cultured in lineage-specific induction media. Multiple animal studies and clinical reports have demonstrated that adipose-derived stem cells repair various defects, including adipose tissue, cartilage, bone and nerve defects (2-4). However, adipose-derived stem cells should be integrated into a scaffold to maintain their position. Hyaluronic acid, which exists in the extracellular matrix, is considered to be a suitable injectable material. Hyaluronic acid-based gels may survive in vivo for 6 months to maintain tissue augmentation $(1,5)$. They may be the ideal scaffold for adipose-derived stem cells, as they have no risk for allergic reaction and provide a favorable environment for cells.

To investigate the potential for the use of adipose-derived stem cells integrated with hyaluronic acid based gel as a dermal filler, the present study investigated the compatibility of adipose-derived stem cells and hyaluronic acid in vitro.

\section{Materials and methods}

Cell culture. All animal experimental protocols were approved by the Ethics Committee of China Medical University (Shenyang, China) and performed according to China Medical University guidelines. Five Male Sprague-Dawley rats (age, 8-12 weeks; weight, 200-250 g) were obtained from the experimental animal department of China Medical University (Shenyang, China). Rats were pre-medicated with Ketalar $(50 \mathrm{mg} / \mathrm{ml}, 0.2 \mathrm{ml} / 100 \mathrm{~g}$ body weight; Jiangsu Hengrui Medicine Co. Ltd., Lianyungang, China), and sacrificed to harvest inguinal fat pad and dissect adipose tissue. The adipose tissue was digested using $0.1 \%$ collagenase type I (V900891; Sigma-Aldrich, Merck KGaA, Darmstadt, Germany) at $37^{\circ} \mathrm{C}$ for $30 \mathrm{~min}$. Dulbecco's modified Eagle's medium (DMEM) supplemented with $10 \%$ fetal bovine serum (FBS) (both from Gibco; Thermo Fisher Scientific, Inc., Waltham, MA, USA) was added for neutralization, and the stromal vascular fraction was separated from the floating adipocytes by centrifugation at 300-500 x g at room temperature for $10 \mathrm{~min}$. The cells in the stromal vascular fraction were resuspended and cultured in DMEM supplemented with $10 \%$ FBS. The adherent cells were reserved by changing the 
culture medium after $24 \mathrm{~h}$, and were passaged 3 times prior to use in further experiments.

Flow cytometry. Rat adipose-derived stem cells from the 3rd passage were lifted with trypsin and washed with phosphate-buffed saline (PBS) 3 times. The cells were incubated with fluorescein isothiocyanate (FITC)-conjugated primary antibodies: Anti-CD29 (SAB4700397, 1:1,000), anti-CD44 (SAB4700189, 1:500), anti-CD45 (SAB4700480, 1:500) and anti-CD11b (SAB4700388, 1:500) (all from Sigma-Aldrich; Merck KGaA), in the dark at room temperature for $20 \mathrm{~min}$. Following this, the cells were washed with PBS and flow cytometry (FACSAria; BD Biosciences, Franklin Lakes, NJ, USA) was performed, the results were analyzed with WinMDI2.9 (developed by Joe Trotter; Purdue University Cytometry Laboratories, West Lafayette, IN, USA).

Cell viability assay. Rat adipose-derived stem cells from the 3rd passage were seeded into 96-well plates at a density of $2 \times 10^{4}$ cells $/ \mathrm{ml}$ with $100 \mu \mathrm{l}$ hyaluronic acid based gel (Shandong Freda Biotechnology Co. Ltd., Linyi, China), and cultured in DMEM supplemented with 10\% FBS. Following culture for $1,2,3,4,5,6$ or 7 days, cells were incubated with $10 \mu 1$ Cell Counting kit-8 (CCK-8) solution (Beyotime Institute of Biotechnology, Haimen, China) at $37^{\circ} \mathrm{C}$ for $3 \mathrm{~h}$. The samples were measured at a wavelength of $450 \mathrm{~nm}$ with an Infinite M200PRO Microelisa reader (Tecan Group Ltd., Männedorf, Switzerland). Adipose-derived stem cells were cultured in $100 \mu 1$ DMEM supplemented with $10 \%$ FBS alone as a control group.

Cytotoxicity study. For the cytotoxicity study, $100 \mu 1$ hyaluronic acid-based gel and $0.5 \times 10^{4}$ adipose-derived stem cells were cultured in $100 \mu \mathrm{l}$ DMEM supplemented with $10 \%$ FBS, and subsequently seeded into 96 -well plates. CCK-8 solution (10 $\mu \mathrm{l}$ ) was added following 3 days of culture. Following incubation for $3 \mathrm{~h}$, absorbance values were detected by a spectrophotometer at a wavelength of $450 \mathrm{~nm}$. Adipose-derived stem cells were cultured in $100 \mu 1$ DMEM supplemented with $10 \%$ FBS alone as a control group.

Proliferation study. For the proliferation study, $100 \mu 1$ hyaluronic acid based gels and $0.2 \times 10^{4}$ adipose-derived stem cells were cultured in $100 \mu 1$ DMEM supplemented with $10 \% \mathrm{FBS}$, and then seeded into 96-well plates. CCK-8 solution $(10 \mu \mathrm{l})$ was added 1, 3 or 6 days following this into the co-cultured system. Following incubation for $3 \mathrm{~h}$, absorbance values were detected by a spectrophotometer at a wavelength of $450 \mathrm{~nm}$.

Apoptosis assay. An Annexin V-fluorecein isothiocyanate Apoptosis Detection kit (Sigma-Aldrich; Merck KGaA) was used to evaluate the effect of hyaluronic acid based gels on apoptosis in adipose-derived stem cells, and $100 \mu \mathrm{l}$ hyaluronic acid based gel and $1 \times 10^{6}$ adipose-derived stem cells were cultured in $100 \mu \mathrm{l}$ DMEM supplemented with $10 \%$ FBS, and subsequently seeded into 24 -well plates. The cells were lifted with trypsin 1, 3 or 6 days later, and resuspended in binding buffer. Annexin-V FITC and propidium iodide were added and incubated in the dark for $15 \mathrm{~min}$. The FACScan flow cytometer (BD Biosciences) was used to detect the effect on apoptosis and the results were analyzed using WinMDI2.9. Adipose-derived stem cells cultured in $100 \mu 1$ DMEM supplemented with 10\% FBS alone served as a control group.

Adipogenic and osteogenic differentiation of rat adipose-derived stem cells. To detect the multipotential differentiation capacity of the adipose-derived stem cells within the hyaluronic acid based gel, rat adipose-derived stem cells from the 3rd passage were used. Once the cells reached $80 \%$ confluence, they were cultured in adipogenic induction medium [DMEM supplemented with $10 \% \mathrm{FBS}$, isobutyl-methylxanthine $(0.5 \mathrm{mM})$, dexamethasone $(1 \mu \mathrm{M})$, insulin $(10 \mu \mathrm{M})$ and indomethacin $(200 \mu \mathrm{M})$ ] for 14 days, orosteogenic induction medium [DMEM supplemented with $10 \%$ FBS, dexamethasone $(0.1 \mu \mathrm{M})$, ascorbate-2-phosphate $(50 \mu \mathrm{M})$ and $\beta$-glycerophosphate $(10 \mathrm{mM})]$ for 21 days. Oil-Red $\mathrm{O}$ and Alizarin Red S staining were subsequently used to confirm adipogenic and osteogenic differentiation of the rat adipose-derived stem cells, respectively.

Scanning electron microscopy. To evaluate the cell attachment capacity of hyaluronic acid based gels, scanning electron microscopy was applied. Briefly, $3 \%$ glutaraldehyde solution in cacodylate buffer $(0.1 \mathrm{M})$ was used to fix the adipose-derived stem cells with hyaluronic acid for $3 \mathrm{~h}$. The fixed complex was subsequently washed with PBS three times. Graded ethanol solutions $(30,50,70,85,90,95$ and $100 \%)$ and hexamethyl disilazane were used for dehydration. The dried complex was coated with $\mathrm{Pt} / \mathrm{Pd}$, and scanning electron microscopy was applied.

Statistical analysis. All data were expressed as the mean \pm standard deviation. One-way analysis of variance followed by Tukey's post hoc test was used to analyze the differences between groups. Statistical analyses were conducted with SPSS13.0 (SPSS, Inc., Chicago, IL, USA). P $<0.05$ was considered to indicate a significant difference.

\section{Results}

Identification of rat adipose-derived stem cells. Rat adipose-derived stem cells isolated from adipose tissue were adhered following 3-4 h culture, and the suspended cells were removed following 24-h culture. The spindle cells demonstrated proliferation from 3 days and colony formation from 5 days, and were passaged after 7 days when they reached $80-90 \%$ confluence. Rat adipose-derived stem cells were successfully obtained at the 3rd passage and were used in subsequent experiments (Fig. 1). Flow cytometry demonstrated that rat adipose-derived stem cells from the 3 rd passage were CD29 and CD44 positive, but CD45 and CD11 negative (Fig. 2).

Cell viability assay. The results of the cell viability assay indicated that rat adipose-derived stem cells within hyaluronic acid proliferated slowly for the first $48 \mathrm{~h}$, but proliferation accelerated from 3 days onwards and appeared to peak at 6 days, which was similar to the results observed for adipose-derived stem cells alone (Fig. 3). 


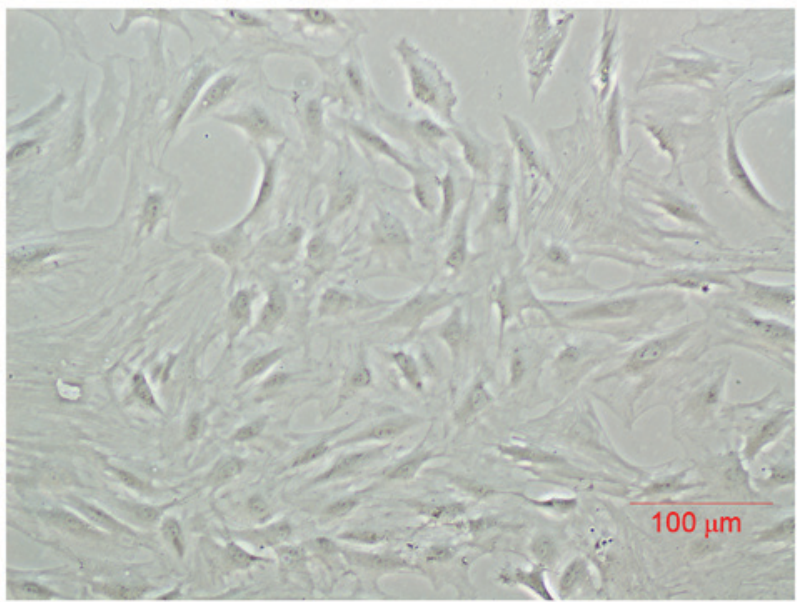

Figure 1. Rat adipose-derived stem cells from the 3rd passage, which formed a large, flat monolayer and were arranged in bundles or whorls. Scale bar $=100 \mu \mathrm{m}$
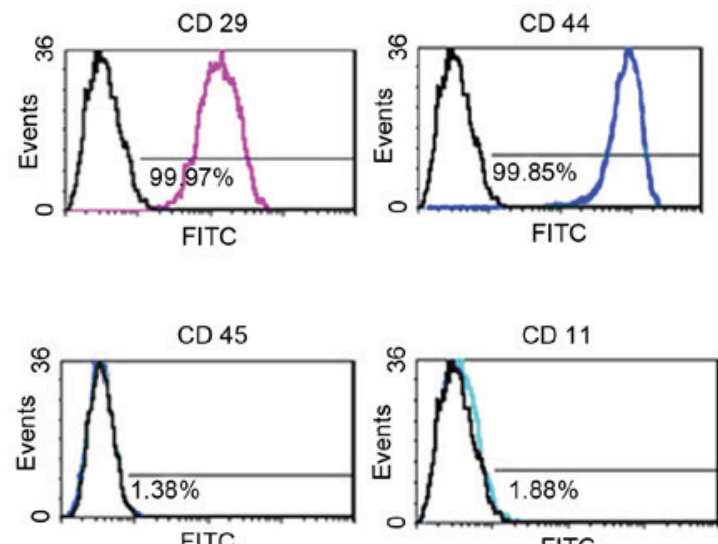

Figure 2. Flow cytometry revealed that rat adipose-derived stem cells from the 3rd passage were CD29 and CD44 positive, but CD45 and CD11 negative. FITC, fluorescein isothiocyanate; $\mathrm{CD}$, cluster of differentiation.

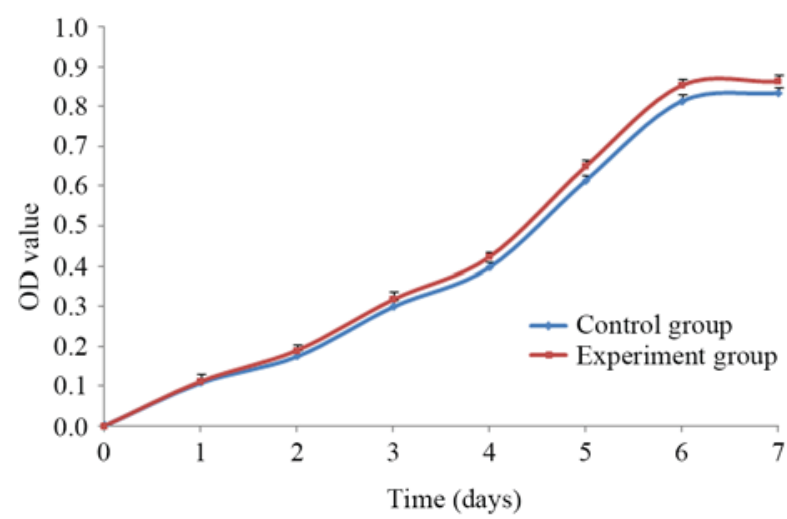

Figure 3. Cell viability assay indicated that there was a lag phase of cell proliferation within the first $48 \mathrm{~h}$, but proliferation increased rapidly from 3 days and appeared to peak at 6 days. Results are presented as the mean \pm standard deviation $(\mathrm{n}=5)$. OD, optical density.

Cytotoxicity study. Following 3 days of culture, the mean absorbance value of adipose-derived stem cells within hyaluronic acid was $0.7471 \pm 0.0129$, and the control group was

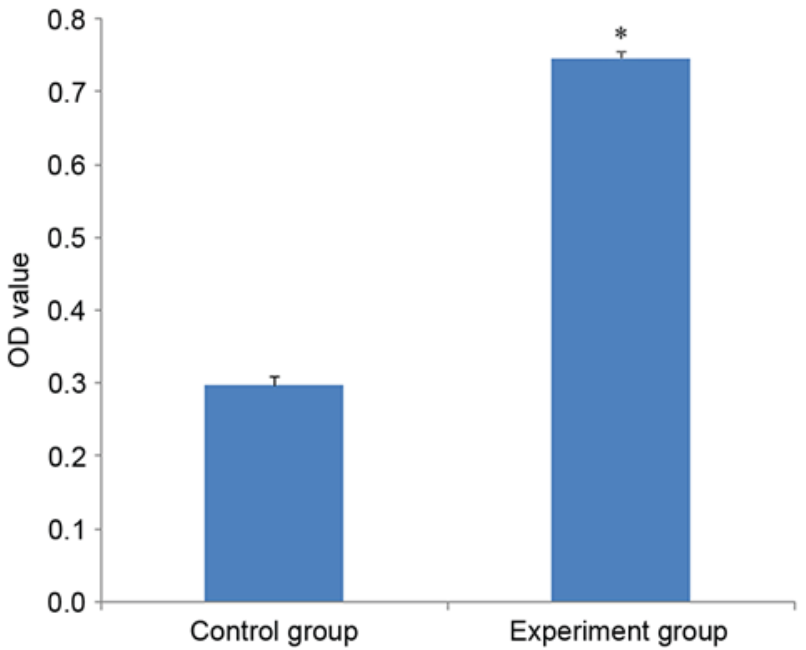

Figure 4. Mean absorbance value of adipose-derived stem cells within the hyaluronic acid based gel experimental group $(0.7471 \pm 0.0129)$ was significantly higher than the control group $(0.2989 \pm 0.0190)$. Results are presented as mean \pm standard deviation $(\mathrm{n}=5)$. ${ }^{*} \mathrm{P}<0.05$ vs. control. OD, optical density.

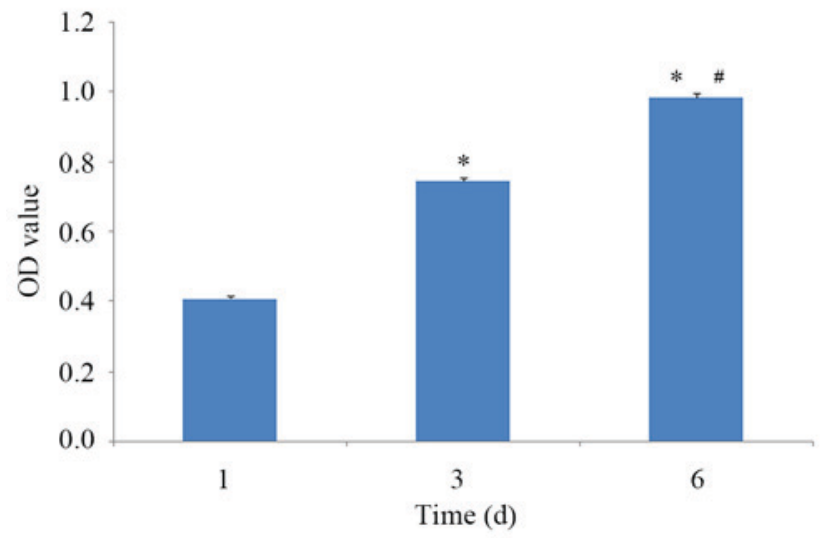

Figure 5. Mean absorbance value of adipose-derived stem cells within the hyaluronic acid based gel at 6 days $(0.9829 \pm 0.0185)$ and 3 days $(0.7471 \pm 0.0129)$ was significantly higher than at 1 day $(0.4089 \pm 0.0156)$. Results are presented as mean \pm standard deviation $(n=5)$. ${ }^{*} \mathrm{P}<0.05$ vs. 1 day, ${ }^{\text {"P }}<0.05$ vs. 3 days. OD, optical density.

$0.2989 \pm 0.0190$ (Fig. 4). This indicated that the cell activity of the group with hyaluronic acid was significantly higher. The results demonstrated that hyaluronic acid was not cytotoxic to adipose-derived stem cells.

Proliferation studies. The mean absorbance value of adipose-derived stem cells within hyaluronic acid at 6 days was significantly higher than that at 3 days $(0.9829 \pm 0.0185$ and $0.7471 \pm 0.0129$, respectively; Fig. 5). This indicated that cell activity of adipose-derived stem cells at 6 days was significantly higher than at 3 days. The results suggested that hyaluronic acid may promote adipose-derived stem cell proliferation.

Apoptosis assay. Cell apoptosis rates at 1, 3 and 6 days were $20.34 \pm 1.53,28.59 \pm 0.48$ and $37.95 \pm 0.93 \%$, respectively. The apoptosis activity of adipose-derived stem cells within hyaluronic acid increased mildly with time, and was higher than the 
A
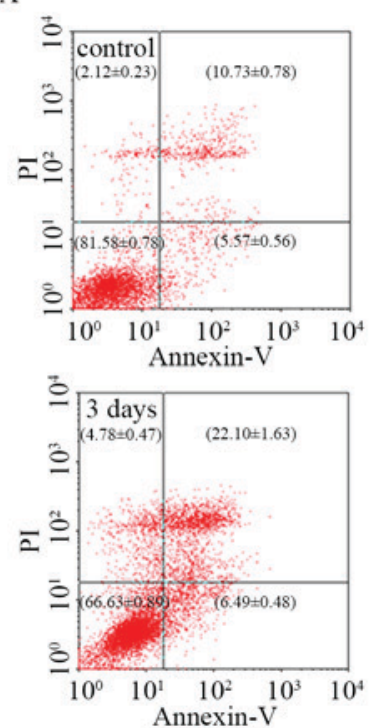
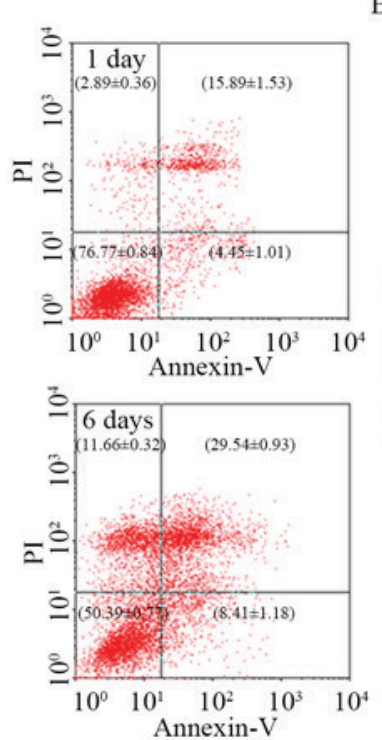

B 100

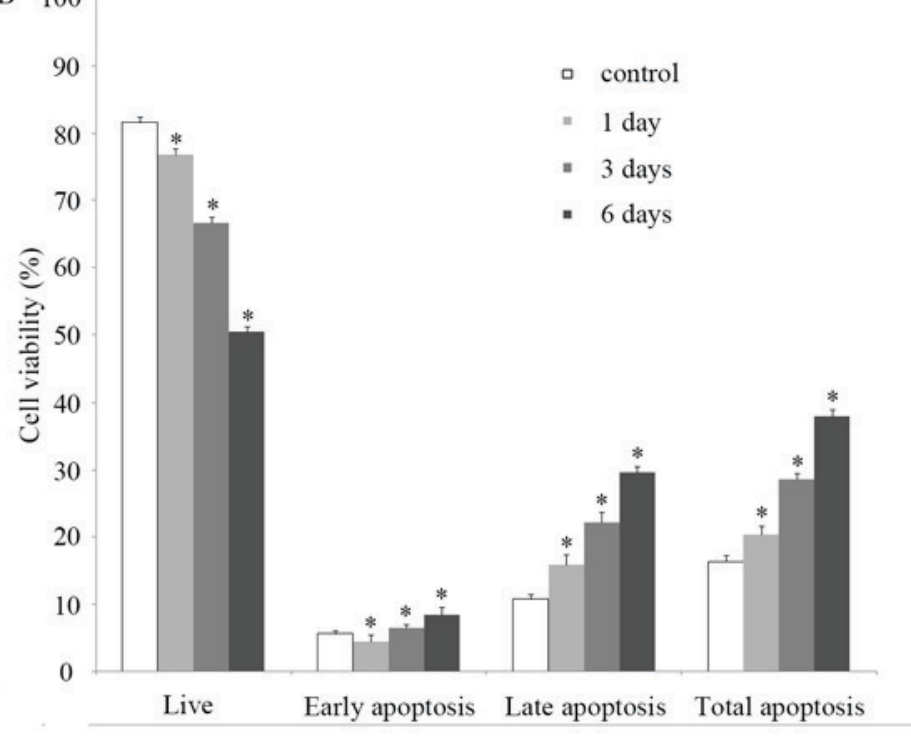

Figure 6. (A) The apoptosis activity of adipose-derived stem cells within the hyaluronic acid gel increased fairly with time, and was higher than control group. (B) Results are presented as mean \pm standard deviation $(n=5)$. ${ }^{*} \mathrm{P}<0.05$ vs. control. PI, propidium iodide.
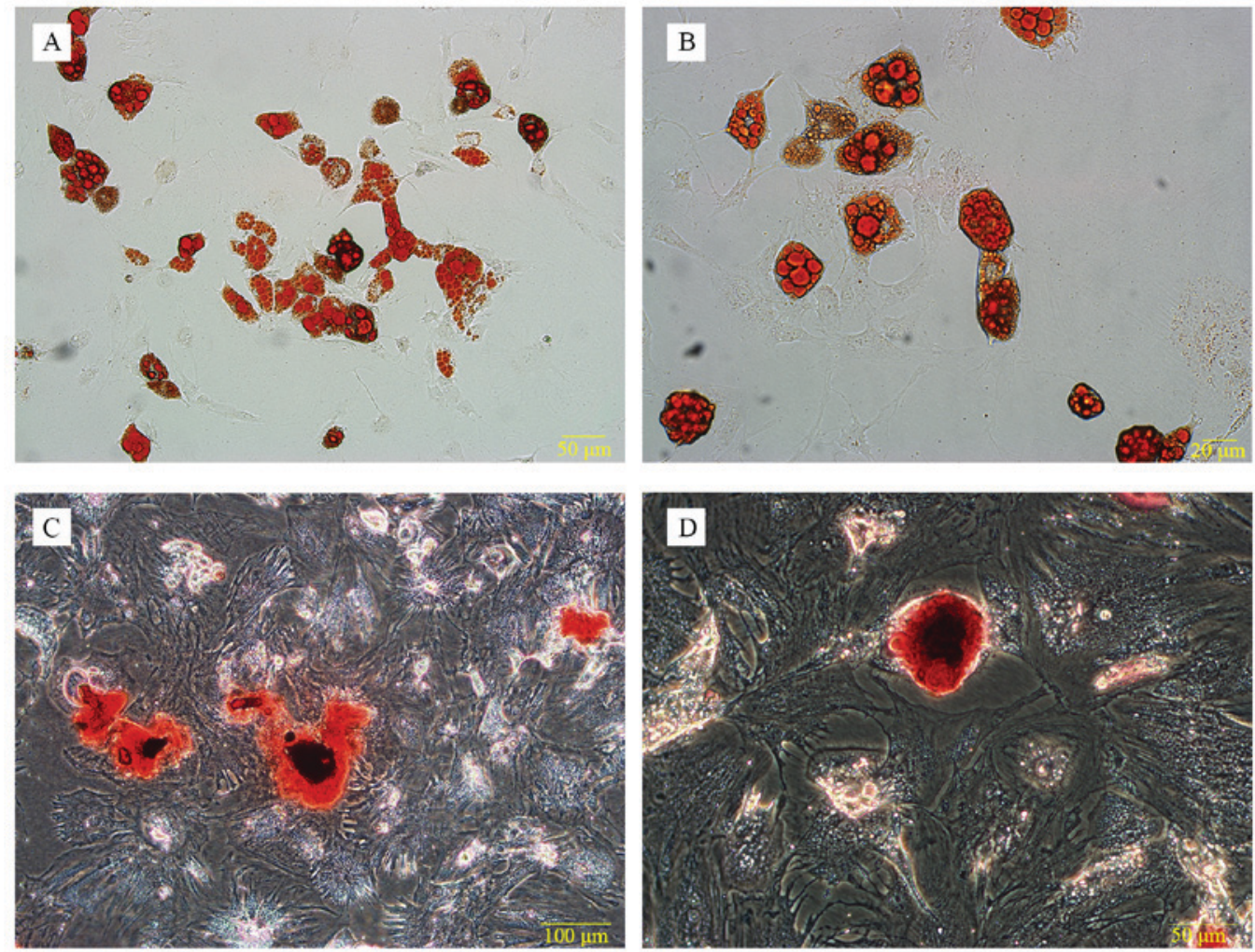

Figure 7. When treated with the appropriate lineage-specific induction medium, rat adipose-derived stem cells within the hyaluronic acid based gel were successfully differentiated into adipocytes and osteoblasts, as confirmed by (A and B) Oil-Red O staining and (C and D) Alizarin Red S staining.

control group, which indicated that hyaluronic acid may induce a fair level of apoptosis in adipose-derived stem cells (Fig. 6).

Adipogenic and osteogenic differentiation of rat adipose-derived stem cells. To verify the maintenance of multipotent differentiation in the adipose-derived stem cells within the hyaluroinc acid gel, adipogenic differentiation was verified by Oil-Red O staining, which demonstrated the presence of intracellular lipid droplets, while osteogenic differentiation was confirmed by Alizarin Red S staining, which demonstrated calcium deposits (Fig. 7).

Scanning electron microscopy. Scanning electron microscopy indicated that adipose-derived stem cells maintained an intact 


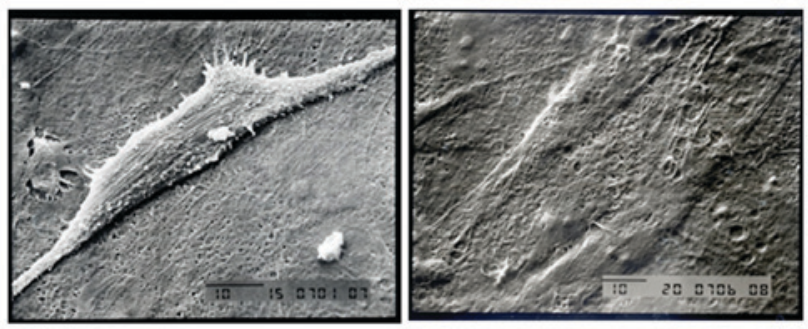

Figure 8. Adipose-derived stem cells maintained an intact structure on the surface of the hyaluronic acid based gel as well as inside it. Images acquired by scanning electron microscopy. Magnification, x1,500.

structure on the surface of hyaluronic acid gel as well as inside it, and demonstrated abundant cell attachments (Fig. 8).

\section{Discussion}

During the last decade, injectable dermal fillers have become a popular treatment to improve facial rejuvenation and wrinkles, correct facial lipoatrophy and provide soft tissue augmentation. Increasing numbers of patient select this method over traditional surgery (1). The ideal injectable dermal filler for soft tissue augmentation should provide structural support, and be safe, effective, long-lasting, biocompatible and not elicit adverse reactions. However, no injectable dermal fillers currently meet this standard, as they give rise to certain adverse reactions $(6,7)$. Therefore, it may hypothesized that integrating two or more known injectable dermal fillers may maximize the strengths whilst minimizing the weaknesses.

The use of adipose-derived stem cells has emerged for plastic surgery, and they are an attractive source for adipose tissue engineering (8-10). Adipose-derived stem cells have an abundant source, are easy to isolate from fat tissue and inject immediately post-isolation, are able to self-renew with a high growth rate, leave limited donor site morbidity and possess multipotent differentiation properties when grown in lineage-specific induction medium. Multiple animal studies and clinical reports have demonstrated that adipose-derived stem cells may repair various defects (2-4). However, adipose-derived stem cells have some limitations. For example, they must be integrated into a scaffold to maintain their position for a short time. The scaffold must be used as a cell carrier upon which cells are seeded, otherwise the injected adipose-derived stem cells disappear and fail to be detected by the Alu gene (11), indicating the adipose-derived stem cells were not able to remain in the injected position without a scaffold. Thus, an absorbable scaffold integrated with adipose-derived stem cells maybe the ideal choice for adipose tissue engineering to augment soft tissue.

The essential properties of ideal cell carrier scaffolds are managed degradation and immunodeficiency (12). At present, hyaluronic acid based gels are the most attractive injectable dermal fillers (13). Hyaluronic acid is one of the main polysaccharides of the extracellular matrix of the dermis, which adds to volume of the skin by promoting keratinocyte proliferation and binding water in the soft tissue, providing support. Experimental studies have demonstrated that hyaluronic acid induces synthesis of type I collagen, which may contribute to providing a preferable microenvironment for adipose-derived stem cells (14-16). Evidence suggests that hyaluronicacid does not stimulate the immune response and is completely degraded by 6 months in patients, leaving no serious adverse effects (17).

Relative to its advantage, hyaluronic acid is usually degraded and reabsorbed after 6 to 9 months (17-19). Therefore, to maintain its effect, hyaluronic acid must be injected repeatedly, which may increase pain and economic burden, in particular in developing countries and less developed areas (20-22).

In the present study, the compatibility of hyaluronic acid based gels with adipose-derived stem cells has been demonstrated in vitro, and they may be integrated with each other as a potential dermal filler. Although our experiment revealed that hyaluronic acid induced a fair increase in adipose-derived stem cell apoptosis, it promoted proliferation of adipose-derived stem cells significantly, indicating that hyaluronic acid may provide a preferable microenvironment for adipose-derived stem cells. Future studies should further investigate the apoptotic rate of adipose-derived stem cells treated with hyaluronic acid, and how this may be controlled.

The present study revealed that adipose-derived stem cells were able to differentiate into adipocytes and osteoblasts. Furthermore, the data demonstrated that adipose-derived stem cells maintained an intact structure on the surface of hyaluronic acid as well as inside it, and demonstrated abundant cell attachment using scanning electron microscopy. This indicated hyaluronic acid may provide a microenvironment suitable for maintaining cell homeostasis and for differentiating tissue properties.

In conclusion, the present study demonstrated the compatibility of adipose-derived stem cells and hyaluronic acid based gels in vitro, with the successful culture of adipose-derived stem cells on hyaluronic acid based gel, cell proliferation, cell toxicity and differentiation assays. Further studies may focus on the combined application of adipose-derived stem cells and hyaluronic acid based gels in vivo.

\section{Acknowledgements}

The present study was supported by the National Natural Science Foundation of China (grant no. 51272286).

\section{References}

1. Eppley BL and Dadvand B: Injectable soft-tissue fillers: Clinical overview. Plast Reconstr Surg 118: 98e-106e, 2006.

2. Zuk PA, Zhu M, Ashjian P, De Ugarte DA, Huang JI, Mizuno H, Alfonso ZC, Fraser JK, Benhaim P and Hedrick MH: Human adipose tissue is a source of multipotent stem cells. Mol Biol Cell 13: 4279-4295, 2002.

3. Shen FH, Werner BC, Liang H, Shang H, Yang N,Li X, Shimer AL, Balian $G$ and Katz AJ: Implications of adipose-derived stromal cells in a 3D culture system for osteogenic differentiation: An in vitro and in vivo investigation. Spine J 13: 32-43, 2013.

4. Yin L, Zhu Y, Yang J, Ni Y, Zhou Z, Chen Y and Wen L: Adipose tissue-derived mesenchymal stem cells differentiated into hepatocyte-like cells in vivo and in vitro. Mol Med Rep 11: 1722-1732, 2015

5. Hamilton RG, Strobos J and Adkinson NF Jr: Immunogenicity studies of cosmetically administered nonanimal-stabilized hyaluronic acid particles. Dermatol Surg 33 (Suppl 2): S176-S185, 2007.

6. Klein AW: Soft tissue augmentation 2006: Filler fantasy. Dermatol Ther 19: 129-133, 2006. 
7. Humphrey CD, Arkins JP and Dayan SH: Soft tissue fillers in the nose. Aesthet Surg 29: 477-484, 2009.

8. De Ugarte DA, Ashjian PH, Elbarbary A and Hedrick MH: Future of fat as raw material for tissue regeneration. Ann Plast Surg 50: 215-219, 2003.

9. Flynn L, Prestwich GD, Semple JL and Woodhouse KA: Adipose tissue engineering in vivo with adipose-derived stem cells on naturally derived scaffolds. J Biomed Mater Res A 89: 929-941, 2009.

10. Itoi Y, Takatori M, Hyakusoku $\mathrm{H}$ and Mizuno $\mathrm{H}$ : Comparison of readily available scaffolds for adipose tissue engineering using adipose-derived stem cells. J Plast Reconstr Aesthet Surg 63: 858-864, 2010

11. Howard D, Buttery LD, Shakesheff KM and Roberts SJ: Tissue engineering: Strategies, stem cells and scaffolds. J Anat 213 66-72, 2008 .

12. Chan BP and Leong KW: Scaffolding in tissue engineering: General approaches and tissue-specific considerations. Eur Spine J 17 (Suppl 4): S467-S479, 2008.

13. Fagien S and Klein AW: A brief overview and history of temporary fillers: Evolution, advantages, and limitations. Plast Reconstr Surg 120 (6 Suppl): S8-S16, 2007.

14. Tezel A and Fredrickson GH: The science of hyaluronic acid dermal fillers. J Cosmet Laser Ther 10: 35-42, 2008.

15. Rohrich RJ, Ghavami A and Crosby MA: The role of hyaluronic acid fillers (Restylane) in facial cosmetic surgery: Review and technical considerations. Plast Reconstr Surg 120 (6 Suppl): S41-S54, 2007
16. Bogdan Allemann I and Baumann L: Hyaluronic acid gel (Juvéderm) preparations in the treatment of facial wrinkles and folds. Clin Interv Aging 3: 629-634, 2008.

17. Stillaert FB, Di Bartolo C, Hunt JA, Rhodes NP, Tognana E, Monstrey S and Blondeel PN: Human clinical experience with adipose precursor cells seeded on hyaluronic acid-based spongy scaffolds. Biomaterials 29: 3953-3959, 2008.

18. Kleinman HK, Philp D and Hoffman MP: Role of the extracellular matrix in morphogenesis. Curr Opin Biotechnol 14: 526-532, 2003.

19. Badylak SF: The extracellular matrix as a scaffold for tissue reconstruction. Semin Cell Dev Biol 13: 377-383, 2002.

20. Huang SH, Lin YN, Lee SS, Chai CY, Chang HW, Lin TM, Lai CS and Lin SD: New adipose tissue formation by human adipose-derived stem cells with hyaluronic acid gel in immunodeficient mice. Int J Med Sci 12: 154-162, 2015.

21. Altman AM, Abdul Khalek FJ, Seidensticker M, Pinilla S, Yan Y, Coleman M, Song YH, Butler CE and Alt EU: Human tissue-resident stem cells combined with hyaluronic acid gel provide fibrovascular-integrated soft-tissue augmentation in a murine photoaged skin model. Plast Reconstr Surg 125: 63-73, 2010.

22. Dietrich I, Cochet O, Villageois P and Rodrigues CJ: Engraftment of human adipose-derived stem cells delivered in a hyaluronic acid preparation in mice. Acta Cir Bras 27: 283-289, 2012. 